\title{
The Effect of Video Analysis on Students' Motivation of Learning Physics
}

\author{
$1^{\text {stExedy C Lampara }}{ }^{1}, 2^{\text {nd }}$ Joel T Maquiling ${ }^{2}$, \\ \{elampara@rtu.edu.ph $\left.{ }^{1}\right\}$
}

\begin{abstract}
Department of CheMaPhy, College of Engineering, Architecture, and TechnologyRizal Technological University, Mandaluyong City, Philippines ${ }^{1}$, Department of Physics, School of Science and Engineering, Ateneo de Manila University, Quezon City, Philippines ${ }^{2}$
\end{abstract}

\begin{abstract}
Video Analysis (VA) is an emerging technology currently used in sports, transportation, and security systems. VA is a method where an actual event is filmed, and the video is analysed and modeled using a software. The software involved generation of numerical values, equations, and graphs. This method can be applied to different experiments, such as those in Physics. However, there is a little knowledge on how this tool affects the motivation of students in learning the subject. In this study, the effect of VA on students' motivation towards learning Physics is investigated. This study was implemented in a high school for six to eight weeks and utilized two groups, the VA group and Non-VA group. Each group comprised of thirty-five Grade 9 students. The study reveals that both groups have statistically indistinguishable self-efficacy $(\mathrm{p}=$ $0.067)$ and stimulation of learning environment $(\mathrm{p}=0.086)$. On the other hand, students who used VA have statistically higher active learning strategies $(\mathrm{p}=0.004)$, Physics learning values $(\mathrm{p}=0.013)$, performance goals $(\mathrm{p}<0.000)$, and achievement goals $(\mathrm{p}=$ 0.003). Thus, students who used VA have higher motivation towards learning Physics than students who did not use it $(\mathrm{p}<0.000)$.
\end{abstract}

Keywords: Experiment, motivation, physics education, technology, video analysis and modeling.

\section{Introduction}

Motivated students have better performance both in academic and in extra-curricular activities. With high level of motivation, they actively participate in class activities, interactive with peers, and enhance their cognitive processes. There are several studies done to enhance their motivation level towards the subject. A study reported that being motivated, along with ability self-concepts, students can achieve better academic performance [1].

There have been innovations in education to increase the motivational level among learners, such as integration of videos in the class. Teachers who used videos in their respective classes have recorded positive feedback from students, it brought flexibility and versability into the class dynamic [2]. Park and Jung [3] reported that video-clips help learners gain positive attitude towards the subject and positively influenced student participation. In addition, it stimulates their interest, improves their concentration, enhances their memory in learning, and provides intelligibility of the lesson [4].

Video is a powerful instructional material and a tool for communication. Through video, documented events are cherished, discussed, and shared among individuals. Accessing 
information from videos uploaded in several platforms provides opportunities. It creates collaborations between students and teachers [5], enhances the services of industry [6], health industry [7], and even transnational transactions [8-10].

According to Puentedura's SAMR Model, videos can be redefined its purpose, from simply showing documented events to an active tool for performing experiments. In recent years, development of software that can analyzed video and provide information is seen. There are several names for the method of analyzing videos such as video content analysis (VCA), video analysis (VA), video tracking (VT), video motion analysis (VMA), video motion detection (VMD), and video analysis and modeling (VAM).

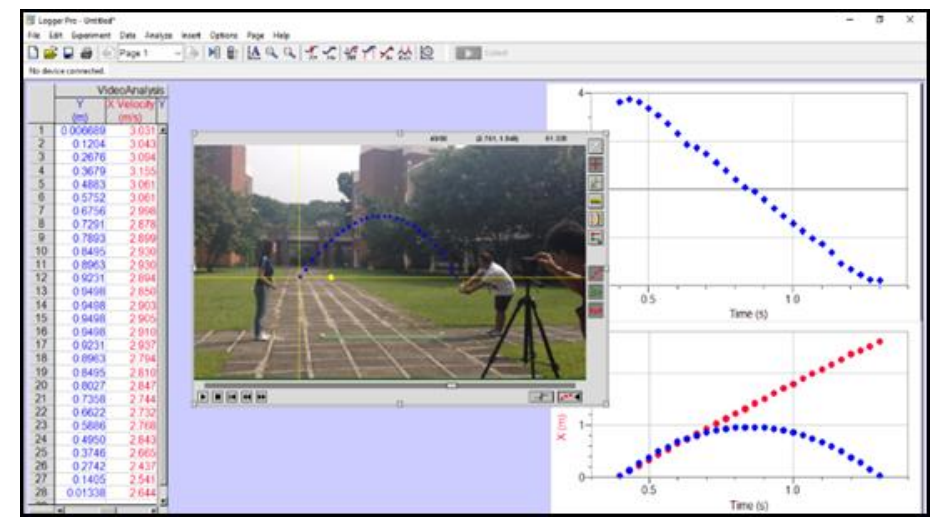

Fig. 1. A ball tossed by a lady is analyzed using the video analysis software LoggerPro version 3.14

The method of analyzing videos is currently used in sports. Seeing the movement of athletes enable coaches and trainers identify the strengths and weaknesses of players. This support system added new inputs for team strategies [11]. Some VA software can determine the dimensions of vehicles, the length, height, and width, for identifying the model of the vehicle [12]. Video analysis can also utilize to determine the movement of vehicles, its lane occupancy, and distance between vehicles to provide information for ride-hailing companies.

The new applications of videos in different disciplines create opportunities in education. The use of video, particularly in tracking motions can also be applied in Physics experiments. Tracking can be done in Physics experiments such as objects falling down inclines and oscillating springs [13], projectile motion [14], and simple harmonic motion [15]. Additionally, the use of VA in Physics class can also improve the becoming-like-scientist attitude of students [16].

Despite the numerous advances of using VA in sports, transportation, security, and Physics education, there is a little knowledge on how this tool affects the behavior, attitude, and motivation of students in learning the Physics. Steinmayr [1] suggests that high level of motivation can lead students to better academic achievement. In this study, the video is redefined as tool in performing Physics experiments. As shown in figure 1, learners' documented activity is processed and analyzed to obtain data and graphs to draw comprehensive conclusion. In particular, the effect of VA on students' motivation towards learning Physics is investigated. This study used the video analysis software LoggerPro version 3.14 produced by Vernier company. 


\section{Methods}

\subsection{Resign Design}

This study used quasi-experimental method. In this design, the respondents are divided in the two groups, the VA group and the Non-VA group. The respondents under VA group utilized video analysis in their Physics class experiments while the respondents under Non-VA did not used it. Before the implementation of the study, the respondents answered a motivational survey adapted from the work of Ben [17] and answered it again when the implementation of the study was done.

\subsection{Research Setting and Respondents}

This study was implemented in a private Junior High School in Mindanao, Philippines. The respondents of the study are the Grade 9 students, academic year 2017-2018. The researchers have chosen the Grade 9 students since the selected topics in Physics that can utilized VA is in science 9 level. The private school has two sections in the Grade 9 level, hence, the researchers used convenient sampling. One section is tagged as the VA group while the other is Non-VA group.

To ensure that the two groups are on equal footing with each other before implementation of the study, their stanine scores in the Otis-Lennon School Ability Test (OLSAT) and grade in Physics in the previous year were compared. Each group is composed of 35 students.

\subsection{Research Instrument and Statistical Analysis}

The motivational survey of Ben [17] was utilized to quantify the motivation of students towards learning Physics. It is composed of 35 statements and is divided into six categories namely self-efficacy, active learning strategies, Physics learning value, performance goal, achievement goal, and learning environment with 7, 8, 5, 4, 5, and 6 statements, respectively. These statements were answered with Likert-scale strongly agree (5), somewhat agree (4), neutral (3), somewhat disagree (2), and strongly disagree (1). The mean Likert scores are described using the interpretation shown in Table 1.

Table 1. Interpretation of the mean Likert scores in motivational survey.

\begin{tabular}{ll}
\hline Mean Score & Interpretation \\
\hline $1.00-1.80$ & Very Negative \\
$1.81-2.60$ & Negative \\
$2.61-3.40$ & Neutral \\
$3.41-4.20$ & Positive \\
$4.21-5.00$ & Very Positive \\
\hline
\end{tabular}

Since the research instrument utilizes ordinal scales, the researchers used independentsamples Mann-Whitney U test to compare the differences between VA group and Non-VA group. 


\subsection{Research Procedure}

After the respondents answered the motivational survey, the study commenced. The teacher used similar pedagogy except on the Physics experiments, where the VA group documented their experiment and obtained data using video analysis while Non-VA group performed and obtained data from similar Physics experiments manually. To avoid biases, three teacher-observers were present during the implementation.

\section{Results \& Discussion}

Prior to the conduct of study, student-respondents answered motivational survey using the 5-point Likert scale. The summary of their responses is presented in Table 2.

As shown, the students under VA and Non-VA groups have neutral level of self-efficacy initially. When their levels of self-efficacy were compared using Mann-Whitney U test, the result suggests that their self-efficacy before the implementation of the study is indistinguishable.

Similarly, the level of motivation of the respondents before the implementation of the study in terms of active learning strategies, Physics learning value, performance goal, achievement goal, and learning environment is neutral. In addition, the motivational levels of the two group are alike.

Table 2. Summary of the results of the Independent-Samples Mann-Whitney U test on the postmotivational Likert-scores of students towards learning Physics.

\begin{tabular}{|c|c|c|c|c|c|}
\hline \multirow{2}{*}{ Category } & \multirow{2}{*}{ Group } & \multicolumn{2}{|c|}{ Pre-Survey } & \multicolumn{2}{|c|}{ Post-Survey } \\
\hline & & Mean & p-Value & Mean & $\mathrm{p}$-Value \\
\hline \multirow{2}{*}{ Self-efficacy } & VA & 2.849 & \multirow[b]{2}{*}{0.345} & 3.690 & \multirow[b]{2}{*}{0.067} \\
\hline & Non-VA & 2.784 & & 3.449 & \\
\hline Active Learning & VA & 3.146 & & 3.939 & \\
\hline Strategies & Non-VA & 3.129 & 0.832 & 3.575 & 0.004 \\
\hline Physics Learning & VA & 3.086 & & 4.137 & \\
\hline Value & Non-VA & 3.091 & 0.920 & 3.723 & 0.013 \\
\hline \multirow[t]{2}{*}{ Performance Goal } & VA & 2.679 & \multirow[b]{2}{*}{0.310} & 4.029 & \multirow[b]{2}{*}{$<0.000$} \\
\hline & Non-VA & 2.621 & & 3.550 & \\
\hline \multirow[t]{2}{*}{ Achievement Goal } & VA & 2.811 & \multirow[b]{2}{*}{0.849} & 3.731 & \multirow[b]{2}{*}{0.003} \\
\hline & Non-VA & 2.817 & & 3.240 & \\
\hline \multirow{2}{*}{$\begin{array}{l}\text { Learning Environment } \\
\text { Stimulation }\end{array}$} & VA & 2.714 & \multirow[b]{2}{*}{0.831} & 3.657 & \multirow[b]{2}{*}{0.086} \\
\hline & Non-VA & 2.724 & & 3.386 & \\
\hline \multirow{2}{*}{ OVERALL } & VA & 2.879 & \multirow{2}{*}{0.503} & 3.850 & \multirow{2}{*}{$<0.000$} \\
\hline & Non-VA & 2.861 & & 3.490 & \\
\hline
\end{tabular}


The post-motivational survey was administered to the two groups to determine the effect of incorporating video analysis in Physics experiments on the motivation of students towards learning Physics. The summary of their answers on the post survey is presented in Table 2.

It was found out that after the implementation of the study, students agree that they developed skills in learning the lessons better. When the students learn Physics concepts, they attempt to understand them, they connect it to their previous experiences, and they find other resources that eases their learning. Although the two groups have similar level of forming strategies to learn, results indicate that students who utilized video analysis improved their learning skill better $(p=0.004)$. This observation agreed with the report of Boateng [18] where learners enabled to have deeper understanding of topics when videos are utilized.

In addition, the results reveal that the students agree that they perceived Physics an important subject because its concepts can be utilized in daily activities, it stimulates their thinking, and it satisfies students' curiosity. The information gap between the Physics concepts and physical activities stimulates their curiosity [19] and this is answered through enhanced activities with the help of VA. Even though both groups improved well, the results suggest that their perception towards learning Physics is distinguishable $(p=0.013)$, with VA group having significantly favorable response towards learning Physics than the Non-VA group. Similarly, the performance goal of the VA group and Non-VA group improved. This means that students participated in the class discussion not just to get the attention of the teacher nor to let others think that they are smart but rather they actively perform their goals to get high grades and to achieve their groups' objectives. Results show that VA group have higher performance goal than Non-VA group ( $\mathrm{p}<0.000)$.

Moreover, students under VA group and Non-VA group improved their achievement goal. After the implementation of the study, students become fulfilled when they got higher scores, when they are confident on the lessons, when they are able to solve difficult problem, and when others accept their ideas. Results suggests that this improvement on students' motivations towards achievement goal is significantly greater when students use video analysis $(p=0.003)$. The learning environment of the students for the two groups were also investigated and analysed. The results indicate that the learning climate of the VA and NonVA group are indistinguishable $(\mathrm{p}=0.086)$. This means that performing and obtaining data from Physics experiments manually has similar learning environment with performing Physics experiments aided with video analysis. This means that the learning climate of the two groups is similar and there is no bias between manually experiment and technologically-oriented experiment.

In general, the motivation of students towards learning Physics improved. Their motivation enhanced from having neutral motivation to significantly higher motivation. However, students who used video analysis and modeling have significantly higher motivation than those students who have not used it $(\mathrm{p}<0.000)$.

\section{Conclusion}

Utilization of video enhances communications and government transactions, improves security services and athletic abilities. Video can be redefined, from simply showing documents events to utilizing it in experiments, especially in Physics, through video analysis 
and modeling. Studies reveal that Physics experiments on oscillation, projectile, and simple harmonic motion can be eased through the use of video analysis.

In this study, the results suggest that performing Physics activities with or without the aid of video analysis improves the self-efficacy of learners. The utilization of video analysis does not change the learning climate of students. It implies that learners perceived technologicallydriven experiments as a good learning platform as to those experiments done manually.

On the other hand, the results of this study reveal that students improve their learning strategies when they utilize video analysis. This means that, with the help of video analysis, students develop strategies that make their learning easy. They look for new ways to understand the lessons such as connecting it with their previous experiences, asking clarification from the teacher, and their classmates. Also, through video analysis, students perceived Physics as valuable subject because they can explain their daily activities scientifically. In addition, students under VA group have significantly higher motivation towards their performance and their sense of fulfillment than students under Non-VA group. Results reveal that students of this group perform Physics activities because they have clear goal of their performance. They also have higher level of motivation because they were to connect their lessons to their daily activities, they were able to solve different problems, their misconceptions were corrected, and they have better scores in tests.

Thus, this study suggests that when students utilize video analysis in their Physics experiments, they improve strategies in learning Physics, perceive Physics as valuable subject, and enhances their performance and achievement goals. Moreover, this study recommends to investigate why technologically-driven Physics experiment and traditional Physics experiments have similar motivational level.

Acknowledgement. The authors are grateful to the Department of Science and Technology of the Republic of the Philippines for funding this study.

\section{References}

[1] Steinmayr R, Weidinger AF, Schwinger M, Spinath B. The importance of students' motivation for their academic achievement - replicating and extending previous findings. Frontiers in Psychology. 2019; 10: 1730.

[2] Bravo E, Amante B, Simo P, Enache M, Fernandez V. Video as a new teaching tool to increase student motivation 2011 IEEE Global Engineering Education Conference (EDUCON); 2011.

[3] Park Y, Jung E. Exploring the use of Video-clips for Motivation building in a secondary School Efl Setting English Language Teaching . 2016: 9(81).

[4] Kosterelioglu I. Student views on learning environments enriched by video clips Universal. Journal of Educational Research. 2016;(4): 359-69.

[5] Al-Mukhaini EM, Al-Qayoudhi WS, Al-Badi AH. Adoption of social networking in Education: A study of the use of social networks by higher education students In oman.Journal of International Education Research (JIER). 2014;10: 143-54.

[6] Kwayu S, Lal B, Abubakre M. Enhancing organisational competitiveness via social media - a strategy as practice perspective Information Systems Frontiers. 2017; 20: 439-56.

[7] Kordzadeh N, Young D. Understanding How Hospitals Use Social Media: An Exploratory Study of Facebook Posts.American Conference on Information System; 2015.

[8] Lu R, Goodale TA. Guo Y. Impact of videoconference with native English speakers on 
CHINESE EFL learners' ORAL competence and self-confidence Open Journal of Social Sciences. 2014;02: 54-60.

[9] Eguchi M . The Effect of Cross-cultural Videoconferencing on EFL Learners' Oral Fluency; 2015.

[10] Denstadli JM, Julsrud TE, Hjorthol RJ. Videoconferencing as a mode of communication.Journal of Business and Technical Communication. 2011;26: 65-91.

[11] O'Donoghue P. Performance analysis research Research Methods for Sports Performance Analysis . 2009; 17-44.

[12] Morris B, Trivedi M. Improved vehicle classification in long traffic video by Cooperating tracker and Classifier Modules 2006 IEEE International Conference on Video and Signal Based Surveillance. 2006.

[13] Bryan JA. Investigating the conservation of mechanical energy using VIDEO analysis: Four cases Physics Education. 2009;45:50-7.

[14] Wee LK, Chew C, Goh GH, Tan S, Lee TL. Using tracker as a pedagogical tool for understanding projectile motion Physics Education. 2012; 47: 448-55

[15] Kinchin J. UsingTrackerto prove the simple harmonic motion equation Physics Education.2016; 51: 053003 .

[16] Kang WL, Kwang LT. Video analysis and modeling performance task to promote becoming like scientists in classrooms.American Journal of Educational Research. 2015;3: 197-207.

[17] BenF. Students' Update of Physics: A Study of South Australian and Filipino Physics Students; 2010.

[18] Boateng R, Boateng SL, Awuah RB, Ansong E, Anderson AB. Videos in learning in higher education: Assessing perceptions and attitudes of students at the University of Ghana.Smart Learning Environments. 2016; 3.

[19] Pluck G, Johnson H.Stimulating curiosity to enhance learning GESJ: Education Sciences and Psychology . 2011; 2:24-31. 